\title{
The world of malaria: a health educational experience in the Colombian Pacific coast*
}

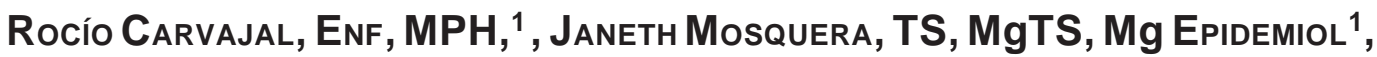 \\ Gabriel Carrasquilla, MD, PhD ${ }^{2}$
}

\section{SUMMARY}

Objective: To describe the design, validation, and implementation of the education material The world of malaria: let's learn to handle it in the community.

Methods: The development of the educational material was carried out in the urban area of Buenaventura (main city in the Colombian Pacific coast) in 1995. The design was based on the results of a knowledge, beliefs, and practices study in the city. By using the PRECEDE- PROCEED MODEL strategy, community groups were brought together with the research team to design the materials.

Results: The educational materials were designed according to cultural and ethnographic characteristics of the population studied. These materials are table games, comics, videotapes and cassettes, magazines, altogether in a black bag called «The world of malaria: let's learn to handle it in the community».

Conclusions: This innovative educational material shows that interventions in public health should be based on results from scientific projects, because control strategies are based on local realities.

Keywords: Community participation; Education; Malaria; Knowledge; Educational materials; Primary health care; Prevention and control.

\section{El mundo de la malaria: una experiencia educativa en salud en la costa pacífica colombiana}

\section{RESUMEN}

Objetivo: Describir el proceso de diseño, validación e implementación de la estrategia educativa «El mundo de la malaria».

Métodos: La estrategia educativa se desarrolló con el modelo de promoción de la salud PRECEDE-PROCEED. Esta estrategia educativa se diseñó a partir de los resultados obtenidos en la investigación sobre conocimientos, actitudes y prácticas en malaria en la población de Buenaventura en 1995. Los grupos comunitarios, el grupo de investigación de la División de Salud de la Fundación FES y los expertos en elaboración de materiales educativos diseñaron la estrategia.

Resultados: Se diseñó y validó un conjunto de materiales educativos acordes con las características culturales y etnográficas de los habitantes de la región. Los materiales educativos constan de juegos, formatos de diagnóstico y seguimiento para el control de la malaria, que se recopilan en un maletín llamado: «El mundo de la malaria: Aprendamos a manejarlo en comunidad».

Conclusiones: El desarrollo e implementación de la estrategia educativa «El mundo de la malaria: Aprendamos a manejarlo en comunidad» muestra la importancia de las intervenciones en salud pública basadas en resultados de investigaciones, lo cual permite generar alternativas de intervención acordes con las realidades locales.

Palabras clave: Participación comunitaria; Educación; Malaria; Materiales de enseñanza; Atención primaria de salud; Prevención y control.

* The Special Programmed for Training and Research in Tropical Disease (TDR) of WHO and the Pan American Health Organization, Ministerio de la Protección Social de Colombia, Plan Padrinos Internacional, Manos Unidas de España, INSALPA-Fundación FES, Universidad del Valle y Secretaria Departamental de Salud del Valle del Cauca.

1. Research, Fundación FES Social, Health Division, Cali, Colombia. e-mail: rocaba70@fundacionfes.org majamos@hotmail.com

2. Professor, Department of Microbiology, School of Health Sciences, Universidad del Valle, Cali, Colombia. e-mail: gabriel.carrasquilla@fsfb.org.co

Received for publication December 7, 2009 Accepted for publication April 13, 2010 
The American region registered an alarming progression of malaria during the last twenty years, going from 270,000 cases in 1974 to over 1.14-million cases in 2000. This situation became a worldwide public health priority, making it necessary to formulate actions to support malaria control within the local context. Among the actions suggested are: the Global Strategy for Malaria Control(GSMC) driven in 1992 and reinforced in 1998 through the Malaria Roll Back program, which are based on the importance of a locally constructed risk approach accompany with actions aimed at controlling vector breeding areas, diagnosis and opportune treatment, the use of bed nets, and community education as an activity to generate behavioral changes ${ }^{1}$.

Strategies for malaria control like broad use of 2,2di(p-chlorophenyl)-1,1,1-trichloroethane (DDT) ${ }^{2}$, adequate and opportune use of anti-malaria medications, and the traditional activities of vertical programs resulted insufficient for malaria control because of the vector's resistance to insecticides and to the parasite's resistance to medications, phenomena described since the late $50 \mathrm{~s}$ and early 60s in Colombia ${ }^{3}$.

Technical and logistic deficiencies in the execution of eradication campaigns and reduction of financial resources destined for national programs, contributed to the resurgence of the disease. Additionally, other measures like vaccinations have yet to show sufficient effectiveness in controlling this disease ${ }^{4}$.

\section{THE CASE OF BUENAVENTURA, COLOMBIA}

Buenaventura is the second biggest municipality in the department of Valle del Cauca; it is also the biggest urban center on Colombia's Pacific Coast and the country's main maritime port. The urban area, where $82 \%$ of its population resides is administratively divided into 12 communes. Of these, communes $9,10,11$, and 12 are the areas with the greatest expansion in the municipality and the principal receptors of displaced and migrant populations from the rural zone and from other parts of the nation. In this city, health indicators are similar to those from the world's poorest zones and much below national figures. Malaria is among the top five causes for ambulatory consultation, hospitalization, and mortality ${ }^{5,6}$. In 1991, Buenaventura registered an increase in the number of malaria cases reported, higher than that reported in the last 15 years. That year, 8,136 cases of malaria were reported of which 3,296 (40.5\%) were registered in the urban zone and 4,377 (53.8\%) in the rural zone ${ }^{7}$.

Since 1958, the activities of the malaria program in Buenaventura had been executed by the Program for Tropical Disease (PTD) (previously known as the Malaria Eradication Service), which conducted spray campaigns, vector controls, along with the disease's diagnosis and treatment in urban and rural areas.

To give an answer to the increasing malaria morbidity, in 1991, through an agreement signed by the Foundation for Higher Education (Fundación para la Educación Superior) (FES), Universidad del Valle and the Valle del Cauca Departmental Secretary of Health, the Health Institute of the Pacific (Instituto de Salud del Pacífico, INSALPA) was created in Buenaventura. Based on findings from study of an evaluation of primary health care services available carried out in ten cities around the nation, in which Buenaventura had the lowest evaluation in the four components of the primary health care strategy $^{8}$, the Institute decided to promote the development of said strategy in that municipality. Thus, INSALPA developed the primary health care strategy for malaria control based on four components: intersectorial, community participation, technological development, and administrative development.

Also, the Institute supported PTD activities destined for malaria control through the development of epidemiological, entomological, and clinical research, as well as administratively and technologically strengthening of the provision of health services. Support activities for the malaria program began with a series of diagnostic studies of the malaria situation, bearing in mind three perspectives: individual, vector, and health services ${ }^{9-11}$ These research results have helped to identify the zones with the greatest malaria transmission in the urban area. Furthermore, in such areas a study was conducted on knowledge, beliefs, and practices (KAP) on addressing malaria, whose results revealed that age (under 10 years of age) and the lack of awareness of breeding areas were risk factors associated with the occurrence of malaria ${ }^{8-11}$. Based on these study results and through a community participation process, an educational program was designed for malaria control.

Study objective. This publication presents the systematization process ${ }^{12}$ of the design, validation, and implementation of this community educational program 
for the purpose of sharing the knowledge obtained through the experience and contributing to improvement of malaria prevention practices in Colombia or in other similar contexts.

\section{METHODS}

Systematization corresponds to a type of qualitative work, which seeks to critically recover social processes $^{12}$. The information was gathered between January and December of 2002 and included documentary review and semi-structured interviews. The documentary information and the interviews sought to explore aspects related to the antecedents, design, validation, and implementation of the educational strategy. The documentary information was recovered from archives at the FES Foundation, at the Valle del Cauca Departmental Secretary of Health, and the Municipal Secretary of Health in Buenaventura. For the interviews, a convenience sampling was carried out with key informants, FES Foundation health researchers, educators, and community leaders who participated in the three stages of the educational program. Once the participants were identified, telephone contact was established to let them know of the study's objectives, methods, and benefits, to obtain their consent to participate in an interview, and, finally, to set an appointment for the interview. The total number of key informants interviewed was 14 of the 17 planned. The three key informants who did not participate were out of Colombia during the research.

For the documentary review, matrixes were designed for information synthesis. A semi-structured guideline was designed for the interviews. The approximately 1 $\mathrm{h}$ long interviews were recorded and transcribed by using Word version 7.0. For their analysis, the complete Word transcription was transferred to Etnograph version 5.0, which included reading of texts, selection, and arrangement of the contents referring to the categories of design, validation, and implementation. The emerging categories were identified and interpreted and the results were explained by then cross-referencing said information with the data obtained from the documentary review.

\section{RESULTS}

Antecedents. The design of the educational strategy was conducted within the framework of a Primary Health Care Program for malaria control developed in Buenaventura. From a series of malaria diagnostic studies, using three perspectives: individual, vector, and health services addressing malaria, the following aspects were identified: 1$)$ the three communes $(9,10,11$, and 12) in Buenaventura with the greatest transmission rates of the disease, 2) the main anopheles species related to the transmition of malaria; 3 ) the bitting rate and schedule; 4) the description of the main breeding areas; 5) the knowledge, beliefs, and practices of the population in Buenaventura in relation to malaria; 6 ) the main risk factors associated with the presence of malaria:age and awareness of the breeding areas ${ }^{8,9}$.

These research results were then used to establish three working areas to fight against malaria: vector control, improved community capacity for diagnosis and treatment, and community education. This led to suggesting the following objectives:

- Increase the population's level of knowledge on malaria as a health problem and on the necessary measures for its prevention and management.

- Train community leaders in the components of malaria prevention and control to diminish the incidence and complications due to this disease.

- Promote community management processes based on adequate attitudes and practices for local malaria control.

From February 1995 until 1997, staggered activities were implemented every six months to constitute community groups for vector control and education in malaria. Twenty-one groups were formed (18 in the urban area and 3 in the peripheral urban area). An average of 23 individuals participated in each group, constituting a total of 300 participants. These were closed groups and the percentage of participation by group members reached $85.6 \%$. At the same time, mommunity leaders were trained through workshops aimed at increasing their knowledge on clinical and public health aspects of the disease, risk factors, and strategies for malaria control. Simultaneously, during 
these two years, the group of community leaders conducted a diagnosis of malaria by neighborhood, established control priorities, formulated action plans, and elaborated community projects to control the disease. All of that resulted in the formation of neighborhood community participation for disease control. It was during the malaria training of the community groups, that the need to produce educational material that would contribute to the population's better understanding of the disease was more evident.

Design of the educational strategy. Once was identified the need to produce educational material to support community interventions being carried out, we invited two professors from Universidad de Chile, experts in educational material design, who conducted training on the design of educational materials with community participation, and participation from INSALPA professionals and community members.

The design of educational material was based on the PRECEDE- PROCEED model ${ }^{13,14}$, which is based on the research-action-participation principle. During the participative design process of the educational material, the characterization of the individuals was the most important aspect for the community. The communities selected characters with afro-descendant characteristics, which is a reflection of a self representation process. Furthermore, the drawings were closed to reality and illustrated every-day life in the Colombian Pacific Coast: typical housing and wardrobe, preference for bright primary colors, and exploration of the language used in the zone ${ }^{15}$. With the participation of three community groups belonging to the 21 vector-control groups, adjustments were made of regional games and tales.

Thereafter, an organization specialized in the production of educational material in the Pacific Coast (Fundación Habla y Scribe) was hired to adapt the language of the texts to the local context, using the every-day language of the community to facilitate comprehension. The sketches were reviewed and modified with the participation of the INSALPA research group, as well as of community groups. In December 1995, a final design of the educational material was done.

Finally, the community groups were called on to suggest a name for the educational strategy. After many initiatives and through a voting process, the following name was opted for «The world of malaria: let's learn to handle it in the community» and it was decided that the most adequate presentation would be a water-proof briefcase adequate for the weather conditions in the Pacific. As a result, the world of malaria consisted in educational materials with images consistent with the language, realism, and colorful characters of the region.

Validation of the educational strategy. The validation of the educational strategy «The world of malaria: let's learn to handle it in the community" consisted in evaluating if the material was interesting, inclusive, and accepted by the communities, and if the messages on malaria knowledge, prevention, and management were clear and understood by the communities of Buenaventura, who would be the main users of the educational strategy.

This validation was carried out in one Communa 12 and it was coordinated by a psychologist. Teachers, community workers, health promoters, community leaders, personnel from the Colombian Institute of Family Welfare, and from the Municipal Secretary of Health, participated in this phase. These persons lead the meetings for the use of the educational material with different groups. These groups met in homes, community halls, health centers, or at the homes of the community agents. The educational material was used in these meetings and the participants aired their opinions on the materials, their characters, the acceptance and comprehension levels of the educational material, and the adjustments that needed to be done to such to make it more understandable and useful.

Implementation of the educational strategy. For the implementation of this educational program, a series of processes were designed encompassing: 1) training of community leaders with special emphasis on opportune diagnosis and self medication, 2) training in activities to facilitate or replicate knowledge on malaria, 3) planning and execution of activities to manage breeding areas, and in the creation of micro-enterprises dedicated to the manufacture of bed nets impregnated with insecticides, 4) training of some leaders in obtaining and interpreting the thick blood smear exam, and in providing malaria treatment. Likewise, a series of instruments were designed to test participant knowledge, to obtain information of the local communities, leaders profiles, and activities for disease control, which have become the materials for the evaluations performed on the educational program whose results have already been 
presented in other publications ${ }^{16-18}$.

The educational material. The main result of the process developed was the design and validation of an educational material called «The world of malaria: let's learn to handle it in the community", created for use by health promoters and volunteers, school teachers, community mothers, and leaders from community organizations. The material was created to be use as a primary prevention tool with the possibility of positively influencing participatory processes for malaria control. The educational material include a set of 17 educational tools, namely:

Participative guideline. It is a consultation booklet for the educational leader which provides methodological guidelines to develop training workshops on malaria with the community.

Booklet «Let's learn about malaria or paludism». This booklet introduces the basic clinical and epidemiological concepts on malaria to guide the educational leader.

Video forum and audio cassette. This is a two-part video. The first part shows a dramatization of a case of malaria in a community, highlighting the way the malaria case should be handled and the community organization alternatives for prevention (control of breeding areas, use of insect repellents, and bed nets). The second part present the community organization processes for malaria control, especially the constitution of a cooperative organization to make bed nets and conducting community activities for adequate environmental management (control of breeding areas and brush clearing). Both the video and the audio cassette performance were made with the participation of the communities from the municipality of Buenaventura. The VHS video presentation lasts 20 minutes.

Cartoon «Let's learn about malaria or paludism». This material presents cartoons of the video and audio contents; designed for communities lacking electronic equipment.

Tale of doña Anofelina. This material aim to identifying the Anopheles mosquito and its life cycle. It targets mainly the childhood population whom shouldplay the tale after reading the material.

Educational games. The four educational games correspond to: What do we know? A game to identify how much do the participants know about malaria. Parcheesi, an individual game made up of cards or indications on individual and collective positive and negative behaviors on malaria control. Bingo and Snakes and Ladders are didactic games, which aid in reinforcing and evaluating knowledge acquired on malaria during the training workshop.

Posters. These tools serve as support to explain the issue of malaria, especially that referring to the main players, its cycle inside the human body, and prevention measures.

Flip charts. This material is used by the leader in the training process. The materials refer to symptoms of malaria, the mosquito's life cycle, and types of breeding areas for Anopheles; different insect species, and mapping of malaria cases.

Achievements. With the implementation of the educational strategy community vector control processes were generated, where 257 individuals of the 300 who initially participated in the design process, were trained during 85 sessions on basic aspects of malaria prevention and control. With these individuals, 50 breeding areas were eliminated and 72 workdays were used in brush clearing. Furthermore, 405 bed nets were made and distributed and 10 days of impregnation were completed. Additionally, 29 community projects were elaborated to identify and eliminate breeding areas and to teach the community about malaria; a community fund was created and 353 accounting and administrative training sessions were carried out that constitute the base of the formation of community groups.

The educational strategy is being integrated onto activities of urban and rural malaria control at the national level in municipalities of Valle del Cauca, Nariño, and Chocó; especially, in activities of Malaria Control Programs in these departments, in Basic Attention Plans - now known as Collective Intervention Health Plan, and in Nariño, mainly, in the alliance established between the Departmental Health and Education Secretaries of Nariño where teachers from malaria infected zones in the department were trained to include them in the educational strategy in institutional educational projects.

Through this educational strategy, community educators from Fundación FES Social have trained a total of 2772 new leaders in 359 locations from the rural area and urban centers in the Pacific region of Nariño, Buenaventura, Chocó, Putumayo, and Amazonas in Colombia; and in Arismendi and Benítez in State of 
Sucre in Venezuela, of which $30 \%$ are health promoters, $24 \%$ microscopy specialists, $17 \%$ leaders from community organizations, $20 \%$ schoolteachers, and $9 \%$ community mothers, and a total of 2772 briefcases of the World of Malaria have been distributed throughout these regions.

This educational strategy evaluates knowledge on malaria through pre-tests and post-tests given to leaders trained. During the years of strategy implementation, it has been possible to establish the percentage of correct answers in the pre-test and post-test; the pre-test of knowledge on malaria has gone from 20 to $50 \%$ right answers and the post-test has reported 80 to $90 \%$ right answers, evidencing increased knowledge.

A total of 518 community malaria control projects (mass distribution of the preventive message, control of breeding areas, brush clearing, filling of wells, drains, and fumigation) have been developed and executed by leaders in the communities. In a follow up after 3,6 , and 12 months of implementation of the control projects, it was found that $73 \%$ (378) of the projects were totally executed, 19\% (99) partially, and 8\% (41) had no type of execution with respect to the activities planned during training. This strategy has been characteristic of creating capacities in leaders and communities where it has been implemented, given that these community projects have been developed in $90 \%$ of the times with the community's own resources.

Though the three annual follow-up activities conducted on those responsible for multiplying the effort (replicators) after the initial training with the strategy's educational materials, we were able to prove by reviewing followup forms collected by the replicators the number of individuals trained by them, the number of activities to manage breeding areas with the community, the types of activities carried out (workshop, visit), and the population group for whom the activity is aimed; in all, the replicator facilitated knowledge to 10,647 people.

\section{DISCUSSION}

Worldwide experiences reveal that community participation is a key element in health promotion and prevention of the disease to maintain or modify life styles and community environments to generate healthier life styles. Communities more involved and committed with health decision making show greater results in terms of their health ${ }^{19}$.

Clear examples showing that community participation is essential in obtaining favorable results for human health are the Carelia Projects in Northern Finland in which mortality via ischemic cardiopathy was reduced by 50\%; or initiatives like those developed in Vietnam, Honduras, and Mexico where provincial and community policies were established to control water containers to control propagation of Aedes larvae, among others ${ }^{20,22}$. Likewise, a national survey in Colombia on malaria control in 184 endemic municipalities reveals important community participation in activities like control of breeding areas with $34 \%$ participation and promotion of the use of insecticide-impregnated bed nets at $14 \%{ }^{3}$.

Promoting the development and implementation of strategies with community participation is, among others, one of the WHO's recommendations for malaria control $^{1}$. The worldwide initiative called «Roll Back Malaria» has insisted on calling on communities for opportune diagnosis, adherence to malaria treatment, and development and consolidation of control programs.

The focus of community participation has been driven by the Colombian government as a fundamental tool for communities at risk to become aware of malaria a problem and an obstacle for their wellbeing, and for the construction -along with health services- of real actions for its control ${ }^{2}$. Within this framework, we register the process developed for the design and implementation of an educational strategy for malaria control «The world of malaria: let's learn to handle it in the community», presented in this document.

This process accomplished the design of educational material according to local characteristics, permitting acceptance within communities and local health agents, as described in the evaluation of processes made on the implementation of the educational strategy, who consider that said educational tool is a major support for local malaria control (Observaciones no publicadas).

The strategy used the PRECEDE-PROCEED health promotion model ${ }^{13}$, which permitted planning an educational intervention against malaria, supported by Research-Action-Participation (RAP), which from a general diagnosis carried out by the community, advanced to the design and implementation of educational processes with the community.

Similar developments, also in Colombia, have been implemented. This is the case for the department of 
Chocó where an educational intervention was conducted with interactive games, yielding increased levels of knowledge with respect to malaria, its symptoms, and the use of anti-malaria medications ${ }^{23,24}$.

Also, Nicaragua has developed programs based on community health education, insecticide impregnation of bed nets, and administration of anti-malaria medications with community volunteers, as key tools to strengthen the inclusion of communities in health actions related to malaria control ${ }^{23-25}$.

The malaria educational experience developed in Buenaventura presents the relevance of conducting interactions between researchers and communities, which permit real social appropriation of knowledge to design interventions in public health based on scientific evidence, enabling the generation of intervention alternatives according to reality ${ }^{15}$.

However, in spite of the responsibility of health services in promoting community participation in disease control, we still find within these institutions a not very active, propositional, and committed role with the processes, which in some instances hinders the sustainability of these types of exercises over time.

The bibliographic review became a limitation for the enrichment of the discussion, because of the rather limited number of publications and systematization of work related to the design and development of health educational material with community participation.

This systematization process ${ }^{12}$ contributed to the documentation and reconstruction of facts surging during design, validation, and intervention of the malaria educational program. And it became a secondary source consultation material for the development of effectiveness evaluations and implementation processes of the malaria control activities proposed by community leaders trained with the strategy and for the costeffectiveness evaluation of the strategy at institutional and family levels, which observed the financial investment versus the number of malaria cases avoided with respect to the implementation of the strategy (Observaciones no publicadas) ${ }^{16-18}$.

The limitations in this study consisted in not having done all the interviews programmed, because three of the key characters were out of the country, as well as not broadening and enriching the document due to the restriction of some aspects in the continuity processes of the memories of the interviewees.
This educational strategy was internationally recognized in 2009 by the Pan American Health Organization, obtaining third place in Latin America as «Champions against malaria in the Americas».

Finally, this article demonstrates how designs of health education strategies for promotion and prevention may be developed with active community participation.

Conflict of interest. None of the authors has conflicts of interest related to this study.

\section{REFERENCES}

1. World Health Organization. Roll back malaria. Washington DC: OMS; 1998.

2. Rojas W, Peñaranda F, Echavarria M. Strategies for malaria control in Colombia. Parasitol Today. 1992; 8: 141-4.

3. Pan American Health Organization, Colombian Ministry of Social Protection. Cien años de Historia 1902 - 2002. Chapter 4. Entre la erradicación de enfermedades y la integración de servicios, 1951 - 1960. Bogotá DC. 2002.

4. Acosta CJ, Galindo CM, Schellenberg D, Aponte JJ, Kahigwa E, Urasa H, et al. Evaluation of the SPf66 vaccine for malaria control when delivered through the EPI scheme in Tanzania. Trop Med Int Health. 1999; 4: 368-76.

5. Departamento Administrativo Nacional de Estadística. Censo 2005. Resumen Nacional. 2005.

6. Solidaridad Internacional. Caracterización de la población desplazada ubicada en el municipio de Buenaventura, departamento del Valle del Cauca, Colombia. Bogotá, DC: Solidaridad Internacional; 2003

7. MéndezF, Carrasquilla G. Epidemiología de la malaria en el área urbana de Buenaventura: análisis de la ocurrencia en el período 1987-1993. Colombia Med. 1995; 26: 77-85.

8. Grigoriu C, Claros LM. Evaluación de las condiciones de gestión para la atención primaria en 10 municipios de Colombia (Tesis). Cali: Universidad del Valle; 1994.

9. Méndez F, Carrasquilla G, Muñoz A. Risk factors associated with malaria infection in an urban setting. Trans Royal Soc Trop Med Hyg. 2000; 94: 367-71.

10. Nieto T, Méndez F, Carrasquilla G. Knowledge, beliefs and practices relevant for malaria control in an endemic urban area of the Colombian Pacific. Soc Sci Med. 1999; 5: 601-09.

11. Olano V, Carrasquilla G, MéndezF. Transmisión de la malaria urbana en Buenaventura, Colombia. Aspectos entomológicos. Rev Panam Salud Publica. 1997; 1: 287-94.

12. Mateus JC, Alvarado BE, Carasquilla JG, Barrera L, Vanegas A, Méndez F, et al. Factors Related to Chloroquine Treatment Failure in an urban area of the Colombian Pacific Coast. 15th International Congress for Tropical Medicine and Malaria, Cartagena, 2000.

13. Morgan M, Francke M. La sistematización: una apuesta por la generación de conocimientos a partir de las experiencias de promoción. Lima: Escuela para el Desarrollo. Materiales didácticos; 1995. p. 1. 


\section{Colombia Médica}

14. Green L, Kreuter M. Health promotion planning:aneducational and ecological approach. $2^{\text {nd }}$ ed. Mountain View: Mayfield Publishing Company; 1999. p. 32-42.

15. Misrachi C. Estrategias y métodos para la promoción de la salud. L0099. Santiago de Chile: Red Nacional de Atención Primaria; 1993.

16. Blumenthal D, DiClemente R. Community-based Hhealth research. Issues and methods. New York: Springer Publishing Company; 2004. p. 171-97.

17. Alvarado BE, Alzate A, Mateus J, Carvajal R. Efectos de una intervención educativa y de participación comunitaria en el control de la malaria en Buenaventura, Colombia. Biomedica. 2006; 26: 366-78.

18. Alvarado BE, Gómez E, Serra M, Carvajal R, Carrasquilla G. Evaluación de una estrategia educativa en malaria aplicada a localidades rurales del Pacífico colombiano. Biomedica. 2006; 26: 342-52.

19. Girón S, Mateus JC, Castellar CE. Análisis de costo-efectividad de dos intervenciones para el control de la malaria en el área urbana de Buenaventura, Colombia. Biomedica. 2006; 26: 37986.
Vol. 41 № 3, 2010 (Julio-Septiembre)

20. Carta de Bangkok para la promoción de la salud en un mundo globalizado. Sexta Conferencia Internacional sobre Promoción de la Salud, agosto de 2005. Bangkok, Tailandia.

21. Organización Panamericana de la Salud. Promoción de la salud una antología. Washington DC: OPS; 1996.403 p.

22. Lloyd L. Organización Panamericana de la Salud/USAID. Proyecto Mejores prácticas para la prevención y el control del dengue en las Américas. [fecha de acceso: febrero 2003]. URL disponible en: http://www.ehproject.org/PDF/Strategic_ papers/SR-7-Spanish.pdf

23. Kroeger A, Meyyer R, Manchno M, González M. Health education for community-based malaria control: an intervention study in Ecuador, Colombia and Nicaragua. Trop Med Int Health.1996; 1: 836-46.

24. Kroeger A, Meyer R, Manchno M, González M, Pesse K. Operational aspects of bednet impregnation for communitybased malaria control in Nicaragua, Ecuador, Perú and Colombia. Trop Med Int Health. 1997; 2: 589-602.

25. Granfield RM, Vermund SH. Health education and community participation in mass drug administration for malaria in Nicaragua. Soc Sci Med. 1986; 22: 869-77. 